\title{
GLOBALISATION VERSUS IBUANYIDANDA ONTOLOGY: CONFRONTING THE TENSION BETWEEN THE "SELF" AND THE "OTHER"
}

\author{
Jonathan O. Chimakonam
}

Department of Philosophy, University of Calabar, Nigeria

jchimakonam@unical.edu.ng

\section{ABSTRACT}

I shall in this paper seek to unravel the challenges which global expansion as it is practised, poses to the understanding of and the relationship between the "self" and the "other" through the mechanism of Ibuanyidanda ontology. Although globalisation tends to collapse borders and promote social cohesion between cultures and individuals at the polar points of the globe, in practice, the relationship which emerges as a result of this global expansion is fraught with inter-racial, inter-tribal and intergroup tensions. My goal is to show that globalisation is not as inclusivist and tolerant in practice as is suggested in theory. I shall explore this by using the problem of ihe mkpuchi anya (the obstacle of passion which inspires a sectional mind-set as opposed to objectivity in human relations), that is identified in Ibuanyidanda ontology.

Keywords: Globalisation; Ibuanyidanda; ihe mpkuchi anya; intercultural philosophy; global expansion

\section{INTRODUCTION}

One of the concerns of philosophy is to solve problems by using the tools of critical reflection, value analysis and the instrument of logic. For this, some philosophers have attempted to describe philosophy as the logical clarification of thought (Ayer 1952: 51). Others, like Kwasi Wiredu, insist that without argumentation and clarification,

\section{UNISA}


there is strictly no philosophy. ${ }^{1}$ Still others, like Antony Flew, emphatically state that philosophy consists of arguments first, last and always (Flew in Omoregbe 1990: 7). These learned opinions only shed light to the ultimate focus of philosophy as a field of study. It should also be noted that every society has its daily worry prompted by circumstances of its existence, which may or may not be peculiar. This is why Russell (1996: 2) states that the circumstances of a people's existence determine their philosophy. For Innocent Asouzu (2004; 2007a,b,c; 2011; 2013), the proponent of Ibuanyidanda theory, one of the main problems facing humanity today is the crisis of relationship resulting from Aristotle's bifurcation of being. The focus of Ibuanyidanda ontology is to correct this great error of thought which has divided humanity into warring factions of an inferiority/superiority tussle between the "self" and the "other".

The question that leads the way is: Is there a strict approach to philosophical enquiry? Aristotle's bivalent metaphysics has been treated as orthodoxy in the history of thought, but Asouzu thinks this is incorrect. For Asouzu, philosophical inquiry could take many approaches, from bivalent to multi-valent logical systems. He, however, favours a multi-valent system where the idea of discrimination and lop-sidedness will be whittled down. Also, Asouzu thinks that some systems, such as the bivalent Aristotelian system, are bad in themselves as a mode of philosophical inquiry. This conclusion of Asouzu appears insightful when we consider the full import of Aristotle's position. By his (Aristotle's) presentation in his book Metaphysics, Aristotle - in employing his preferred bivalence principle - seems also to draw a line between what is of essence and what is not. Ontology for him consists of the substance (which is essential) and accident (which is not) (Aristotle 1926: Book A, $2,6,8)$. As a matter of fact, it is the substantial that characterises being. In his words "if these are not substance, there is no substance and no being at all; for the accidents of these it cannot be right to call beings". ${ }^{2}$ This sort of thesis has wider implication not only in metaphysics but also in all the sciences of human relations because the same line runs through race, faith, gender and ethnicity; and also between the "self" and the "other". These are some of the most dangerous problems of humanity today.

Asouzu therefore discountenances the philosophy of essence on the basis of this lop-sidedness and greater human relationship implications. ${ }^{3}$ By rejecting Aristotle's philosophy of essence, he inevitably rejects the logical principle of bivalence which

1 Wiredu, Kwasi. Philosophy and an African culture. Cambridge and New York: Cambridge University Press, 1980, p.47. Apparently, Wiredu was influenced to this line of thought by the logical positivists.

2 Aristotle 1926: Book B, 5. Even though Aristotle admits that accident is an attribute of being, he clearly establishes it as dispensable. Thus, in intercultural relationships brought about by global expansion, mere admission that the other exists does not usually translate to equal treatment.

3 Asouzu 2011: 16-17. The reason behind Asouzu's vehement opposition to theories that espouse dichotomies is that they provide room for each dichotomy to carry attitudes of ethnocentric commitments in their relationships with the other. 
presents reality as polarised into two extremes, excluding the intermediary positions. In its place, Asouzu seems to favour a multi-valent system of thought which recognises the possibility of different sub-positions in-between two extremes (Asouzu 2013: 90109). Thus, Ibuanyidanda ontology holds that reality is not dichotomised, bifurcated or polarised. Every reality serves a missing link in a complementary relationship of all there is (Asouzu 2004: 277-79).

In this work, I intend to provide a background to Asouzu's Ibuanyidanda philosophy. I will then discuss the idea of global expansion as a conflict between homogenising and differentiating forces. I will attempt in the process to bring out the full import of Aristotle's dichotomising metaphysics in the creation of tension between the "self" and the "other" in our world today. I will offer Asouzu's Ibuanyidanda ontology in light of its complementarity as a viable alternative for reconstructing being from the perspective of its interconnectedness and interrelatedness. Finally, I will raise some possible objections, especially to the framework of Ibuanyidanda philosophy, and offer responses to its credibility.

\section{THE MAIN THRUST OF IBUANYIDANDA PHILOSOPHY}

Ibuanydanda is a theory of being from an African perspective, formulated by the Nigerian philosopher Innocent Asouzu. A teacher of philosophy for many years at the University of Calabar, Asouzu weaves the basic tenet of his ontology in the dense idea, that "being is that on account of which anything that exists serves a missing link of reality" (Asouzu 2011: 41).

The science of ontology investigates being, its structure and relationships (Lawson 2004: 2). The processes of this inquiry portend some challenges in that biases and idiosyncrasies associated with conceptual and theoretic frameworks, sometimes affect the outcome of the investigation. The Aristotelian essentialist framework, for example, which bifurcates being into substance and accident, ultimately affects the outcome. It could lead to a theory of being in which reality consists of mutually exclusive entities and of absolute identity and absolute difference (Sogolo 1993: 68-69). This type of structure entails great problems in the human society where humans are existentially in need of complementation of one another's efforts. It is to address the challenges that face ontology that Ibuanyidanda was born as a veritable alternative episteme.

The concept Ibuanyidanda comes from the Igbo language. As a matter of fact, it is a maxim "ibu anyi danda" which means, "no load or burden is beyond the capacity of a certain species of gregarious ants to bear". Asouzu gleans inspiration from the organisation and complementary attitude of this species of ant to construct a philosophy for all of humanity. He, however, distinguishes ibu anyi danda as a descriptive hypothetical injunction from his system Ibuanyidanda - written as one word - which he elevates to a categorical imperative. This thought centre, for him, 
creditably rivals Aristotle's conception of being, which is polarising. According to Asouzu:

Since our tension-laden ambivalent existential experience and ihe mkpuchi-anya (phenomenon of concealment) often mislead us into assuming that life is a struggle involving irreconcilable opposites, Ibuanyidanda ontology seeks ways of reconciling the apparent ontological tension between being and its attributes. This type of tension found its way into Metaphysics by certain specifics of Aristotle's doctrine of being. (Asouzu 2013: 60)

In his Metaphysics, as we earlier observed, Aristotle draws a prejudiced line between substance (essence) and accident of being (1926: Book B, 5). The former is the ultimate character of being. It is indispensable in the analysis of ontology, whereas the later accident is dispensable. As a matter of fact, substance can subsist without accident while the reverse is not the case. It is the substance of a thing that accounts for its existence. Obviously, Aristotle's ontological framework is lopsided; it vitiates one aspect and elevates the other akin to the disharmonious "self" versus the "other".

Asouzu traces this as the bastion of all irreconcilable opposites in philosophy as well as the world. For him, most extremist and seemingly irreconcilable positions derive their momentum from this distinction, be it those between rationalism and empiricism, between essentialism and existentialism, between idealism and realism, etc. (Asouzu 2013: 60). Asouzu further states that if substance and accident are as distinct to each other, as Aristotle seems to suggest, then the world is constituted of irreconcilable ontological opposites and this spells doom for humanity and civilisation in general (Asouzu 2013: 60).

Asouzu therefore holds that reality is not consisted of irreconcilable extremes, as Aristotle's framework makes it appear. Ibuanyidanda as an alternative veritable framework bespeaks of a dynamic theory of ontology as against the static Aristotelian ontology, which has become the blue-print of Western metaphysics. In the Ibuanyidanda ontology, some of the challenges which vitiate ontological inquiries are: ihe-mkpuchi anya (phenomenon of concealment) which blindfolds us into seeing reality as twines of conflicting opposites; unintended ethnocentric commitments which commit us to elevate the "self" over and above the "other"; misinterpretation of the act of existing as the capacity to be alone leading to such negative maxims as ka so mu di (that I may be alone); introduction of undue rivalry in the scientific community which often leads inquirers into drawing a line between the superior and the inferior, etc. (Asouzu 2011: 16-32).

Ibuanyidanda seeks then to transcend the static, dichotomous ontological framework propounded by Aristotle into a complementary consciousness where every reality exists in a network of mutual complementarity. There is nothing that is meaningless, useless or valueless. Everything exists for others and serves a missing link in the gamut of reality. In doing this, Ibuanyidanda finds a way of overcoming the challenges of ontology. 
To overcome some of these challenges, Asouzu (2011: 46-56) recommends three Ibuanyidanda antidotes, namely (i) noetic propaedeutic, which is a pedagogical therapy for the obfuscated human mind. This entails the re-education of the mind to understand the proper and correct structure of existence; (ii) recourse to the transcendent categories of unity of consciousness (akara-obi/akara ттио) which is the stream of consciousness that helps the human mind go beyond the pressured existential conditions and see the shared values of humanity; (iii) full personal autonomy through ima-onwe-onye (being in control) - a pure being is a being that is in control of itself and not the one that is arbitrarily determined by ethnocentric conditions and human ambivalent circumstances. It is in this way that the challenges of ontology would be overcome.

"To be" is to be in a mutual complementary relationship, whereas "being" is that on account of which everything that exists serves a missing link of reality. It is when these conditions are met in an effort to conceptualise Ibuanyidanda ontology, that we talk about ima onwe onye - or being-in-control as an important attribute of an authentic being. A being has to be in control of itself in order to be able to approach its quest for truth from an unbiased angle of the framework provided by all missing links of reality, otherwise it would not be an authentic being. Accordingly, Asouzu remarks that:

It is for this reason also that philosophy, when articulated as a discipline, is nothing other than the science of being through which the thinking subject seeks to address the ambivalence arising from his world, as a being-in-control. This is why for complementary reflection, to be is to be in control and this is the moment human reason seeks truth from its entirety. Here, any philosophy that is articulated outside of the framework provided by all missing links, in their complementary interrelatedness, merely seeks to distort the idea of truth itself. (Asouzu 2007b: 225)

What ima onwe onye portends is the restoration of full personal autonomy from the presentment of a common web of mutual existence of all realities. Yes, realities exist as mutually interrelated and inter-dependent and affirm their existences within the framework provided by all missing links of reality, but at the height of this consciousness is the full personal autonomy of individual beings. At this level, no being requires policing or monitoring to observe the imperative of Ibuanyidanda. This is why Asouzu declares that such is the highest form of self-consciousness through which "the thinking and acting subject comes to authentic personal insight into the fact that to be is the capacity to be in control of our tension-laden existential situations and the phenomenon of ihe mkpuchi anya" (Asouzu 2011: 54). Therefore, Ima onwe onye is a transcendent act where actors attain the consciousness that to be and to exist entail being in control of all tension-laden existential situations in the realisation that all existents serve missing links of reality.

Ima onwe onye is also by the above opposed to all anti-Ibuanyidanda mindsets such that magnify the differences and silence similarities among all realities. 
Asouzu also explains that consistent self-interest is anti-self-interest. Recourse to the super-maxim or the danda rule (the nearer, the better, the safer) which is a strong manifestation of anti-Ibuanyidanda mind-set, is at this level of consciousness suppressed as actors act freely without predeterminations. Ima onwe onye encourages inclusiveness and discourages exclusiveness. In fact, a being that has attained full personal autonomy, Asouzu explains, cannot err culpably. ${ }^{4}$

Because of the need to transform the descriptive hypothetical injunction "ibu anyi danda" to a categorical imperative "Ibuanyidanda", a designating framework has to be erected. This is what Asouzu calls the transcendent complementary circle that will provide the context for determining the Ibuanyidandaness of any given judgment or action (Asouzu 2013: 72). Conceived more broadly, Asouzu states that this transcendent circle will enable the metaphysician focus on the Ibuanyidandaness of any given entity, phenomenon or event (Asouzu 2013: 72). So the question is, how can the transcendent complementary circle be achieved? Asouzu writes:

To achieve this, there is need for the human consciousness to be trained to approach reality in transcendent complementary comprehensive future related mode. This can hardly be realized where the very tools needed to attain this herculean task do not reflect the character of the undertaking itself; namely, steering reality in a transcendent complementary comprehensive future related mode; and affirming same as missing links of reality. Hence, ignoring the mutual complementary connection between these tools - the method, the truth and authenticity criterion, the principles and imperatives of Ibuanyidanda - would always lead to a distortion of our picture of the world. (Asouza 2013: 72)

What Asouzu explains in the above is that the transcendent complementary circle is a level of consciousness attainable through a form of mental therapy called the Noetic propaedeutic (Asouzu 2007a: 199). Noetic propaedeutic is a process of reeducation or re-orientation that teaches the subject how to define its interest within the framework of the totality. Actors are taught that in the natural ontological scheme of things, their being depends on mutual complementary relationship with all things that exist. Asouzu argues that this consciousness is not pre-given, which is why it has to be gained through the process of complementary noetic propaedeutic (Asouzu 2007a: 200). Therefore, it is in this process of re-education of the mind that a subject comes to realise the inherent connection between its being and those of others, where each serves a missing link to the gamut of reality. It is that necessary connection or imperative network that characterises relationship at that level, which accounts for the transcendent complementary circle in Ibuanyidanda ontology. At that level of consciousness, actors realise that what touches one, touches another; that to strive to protect one's interests against those of the other, amounts to the negation of one's self-interest; that proper legitimacy to actions and interactions is granted by all

4 Asouzu. 2011: 56. Asouzu definitely implies the famous Socratic dictum that it is ignorance that causes evil doing. 
missing links of reality, thereby making static individualistic ontology moribund and untenable.

Evidently, it is at this level where a transcendent complementary circle is formed that the descriptive hypothetical injunction ibu anyi danda gets transformed into a categorical imperative Ibuanyidanda. According to Asouzu, as soon as this is realised, we notice that Ibuanyidanda comes with a boomerang effect such that is enshrined in the Igbo adage "egbe bere ugo bere nke si ibeya ebekwana nku kwaa $y a$ " (Asouzu 2007c: 391-92) i.e. whichever unit in the network of realities makes life difficult for the other, creates the necessary condition for severance of its own existence. This is why Ibuanyidanda is a categorical imperative; a universal law beyond mere hypothetical injunctions.

"Being as a missing link of reality" is an important cliché in complementary reflection. It is a thesis statement of complementary ontology and the grand summary of Asouzu's thought. The focus of complementary ontology is to unravel being from an Ibuanyidanda/African perspective. This is why in his definition of being, Asouzu states that being is that on account of which anything that exists serves a missing link of reality (Asouzu in Chimakonam 2015: 51). The assertion "anything that exists serves a missing link" as maintained naturally forms a central methodological thesis of complementary reflection as a philosophy of integration and transformation. Its root influence is the context of traditional African existential experience (Asouzu 2004: 277).

The idea of a missing link encapsulates the state of reality as a web or network of all existents in which everything that exists somehow factors in. In this way, every reality has a place in this web. Its absence automatically constitutes a missing link. By missing links Asouzu means the diverse units that make up an entity within the framework of the whole and as they are complementarily related (Asouzu in Chimakonam 2015: 41). What this shows is that every variable in existence is a missing link in the network of reality as whole.

Taken under this context, individual beings constitute missing links of reality. As units, they each factor in the common web of existence, each needing the other. The inter-dependence and inter-relatedness of reality is made manifest in this whole. That every being serves a missing link of reality, accounts for the necessary complementarity that must exist among them. Thus a missing link captures a central mode of expression of being (Asouzu 2007a: 267). Hence, to be is to be in a mutual complementary relationship. This suggests agreement with the thesis of globalisation, which seeks to breach the gap between cultures and by extension individuals in those cultures, but the extent to which globalisation succeeds in this is open to questions. In this essay, I uphold the position that in relaxing the borders and bringing individuals of various cultures together, a form of relational tension would be created based on the pre-existing cultural predeterminations that make one culture feel a certain measure of disdain for the other. The mode of occurrence, effects and 
management of this tension shall constitute the focus of a later section. Right now, I will address the question of globalisation.

\section{THE QUESTION OF GLOBAL EXPANSION}

In their work, Critical theories of globalization (2006: 13), Chamsy El-Ojeili and Patrick Hayden produce a short list of interesting definitions for globalisation: beginning with Calhoun who conceives globalisation as "A catch-all term for the expansion of diverse forms of economic, political, and cultural activity beyond national borders" and Bauman who states that globalisation has to do with "timespace compression". These two simply refer to the much horned ability of an elite culture to transcend boundaries and extinguish other human erected limitations. However, questions have been and can still be raised whether globalisation actually lives up to this billing. To this end, El-Ojeili and Hayden (2006) go on to cite Roland Robertson who sees globalisation as "the crystallization of the entire world as a single place" suggesting not only the possibility of globalisation to accomplish the so-called time-space compression but its very actuality. To cap it all, John Lechte for them, defines globalisation from the point of connectedness, which according to El-Ojeili and Hayden (2006) is suggested in Marshall McLuhan's 1962 phrase "the global village", which literally regards globalisation as an emerging global consciousness. ${ }^{5}$

On the whole, the idea which runs through these various definitions, and which is of interest to this paper is that of the anticipated harmonious interconnectedness and interrelatedness of all humanity made possible by globalisation. It is my argument in this essay that this anticipated global consciousness would nonetheless be characterised by an uneasy tension, where various peoples of diverse cultures carry certain ambivalent predetermination, whether consciously or unconsciously against the "otherness". It is at this point that I find a link between globalisation (which seeks among others to breach the gap between the one and the other) and Ibuanyidanda theory (which seeks to emphasise the interconnection that should characterise the relationship between the one and the other). This link further suggests the cause of the relational tension between the one and the other captured in Ibuanyidanda theory as ihe mkpuchi anya (phenomenon of concealment) (Asouzu 2011: 29-30). Asouzu explains this phenomenon thus:

Regrettably, again, steering a course of mutual complementation and harmony is not always an easy task, since all human existential situations in addition to being ambivalent have an inherent dimension of what we call in Igbo language ihe mkpuchi anya (the phenomenon of concealment). Literally this translates to: "the thing that covers the eyes" or "the thing

5 Chamsy El-Ojeili and Patrick Hayden. 2006. Critical theories of globalization. New York: Palgrave Macmillan. 13. I have decided to refer to these conceptions shortlisted by El-Ojeili and Hayden because they capture the idea of globalisation I intend to work with in this essay. 
that impairs vision". If the ambivalence points at the double capacity of our interests and the world in general, the phenomenon of concealment (ihe mkpuchi anya) points at our ability to mismanage this ambivalence. In all existential situations, actors are constantly exposed to the dangers of error of judgement in their relationship to the world, due to this ambivalence and ihe mkpuchi anya. We encounter an instance of such an error of judgement when, in our encounter with the world, we usually believe that 'the nearer the better and the safer' and adopt this as a general principle that guides our action. Generally and naturally, we perceive and adjudge those nearest to us better and safer, but this must not always be the case since those nearest to us are not always the safest and best. (Asouzu, The Challenges of Super-maxim to Judgment and Actions, xix.) It is due to our disposition to commit errors of judgment of this kind, that actors also have the innate tendency to resolve conflicts in a one dimensional absolute mode and by recourse to extreme and polarising measures. Even if ihe mkpuchi anya is an existential condition that impacts on the individual, it can evoke a depraved exclusivist, non-conciliatory collective consciousness, when concerned individuals unite in pursuing certain interests they cherish most. (Asouzu 2012: 29-30)

Thus with the presence of ihe mkpuchi anya, the impact of global expansion is bound to carry uneasy tensions. Globalisation as an ideology and a movement narrows down to all ramifications of interpersonal, inter-group and intercultural interactions, which make little sense of the limitations of boundaries and spaces. However, Ibuanyidanda philosophy through ihe mkpuchi anya (phenomenon of concealment) reveals that humans and cultures are always at war with one another against the realisation of global exchanges, though unwittingly. Even at the collapse of cultural borders through global expansion, actors carry with them what Asouzu calls unintended ethnocentric commitments (Asouzu 2007b: 25-63) in their relationships with the other, striving always to protect and place the ethnic or clan or racial or group interest above that of otherness. The effect of this tension which could be epistemological, ethical or ontological, impairs people's capacity to "know", to "judge" and to "will" with regards to the other and vice versa. The reduction from this is that globalisation actually fails in some of its promises, thus engendering and sustaining tensions between polar points of human relations.

A question must be asked: What constitutes this tension? Whether artificial or natural, it is readily observable that the world of humans is lopsided and rides on the crest of discrimination between the well-offs and the not-so-well offs; the superior and the inferior; the civilised and the non-civilised; or simply put, the "self" and the "other". This consciousness that one is better or superior to the other, undergirded by Aristotle's polarising metaphysics, is likely going to birth a strong tension in the relationship or interactions between the peoples and cultures of the world as soon as globalisation collapses the national boundaries. This tension very often orchestrates severe frictions that go on to demolish the structures of political, social and religious stability in different parts of the world. For example, it is the belief that the foreign policies of the Western countries, especially the USA, are aimed at drawing a line between the superior West and the inferior Arab, that the architects of 
Al Qaida claim spurred them to begin what they called a Jihad. The ripple effect of Osama Bin Laden's campaign has reached many parts of the world with unnerving consequences. In Africa, for example, there is Al Shabbab in Somalia and Boko Haram in West Africa; both of which have drawn inspiration from the terrorist networks in the Middle East.

Indeed, wherever these terror networks arise, they uniformly claim the need to resist Western domination as their common goal. The mass executions carried out by these organisations like ISIS, Boko Haram, and their loyalists in other countries, have been projected as a reprisal against the domineering West and their cronies. Whether the presupposition of these terror groups is correct or even right is of little importance here. What we seek to bring to the fore is the often neglected tension created between the "self" and the "other" in the event of global expansion by the consciousness that seeks to polarise and bifurcate humanity into the offending "self" and the defending "otherness". Whither globalisation?

If globalisation, as Agbo (2010) conceives it, is an advocacy for cultural integration of the peoples and the nations of the world, which is supposed to be the direct result of increase in communication, interaction and info-technology, and is aimed at further uniting humanity, then why is this process seriously threatening and in many ways and places jeopardising the peace of the globe? What sort of consciousness is the globalising process breeding? And why? The apparent disdain with which some elements in the global South treat globalising trends - regarding it more as a product than a process; in which the West feels entitled to impose its determined structures on the rest of humankind viewed as inferior, clearly accentuates the idea of globalisation as a cultural colonialism. It is in this connection that Agbo (2010: 35) raises the critical question: Is globalisation a process or a product? In response he argues that globalisation, as the name portends, ought to be a process which sees to the elimination of national borders and egos, but its actual practice has presented it more like a product which a superior/determined culture sells or imposes on the inferior other (Agbo 2010: 26-38). As a product, therefore, globalisation is wont to undermine the local and less developed cultures and civilisations. It seeks to project the culture of the "self" as not only superior but the very standard of civilisation, which the global South or the less developed "otherness" must ape.

Therefore, globalisation fails to harmonise the world's citizens, although it appears to be succeeding in eliminating national borders, the disgruntled consciousness of humanity halved into the one who looks disdainfully at the supposedly marked inferior "other"; and the other who looks angrily at the supposedly marked superior one, cannot but be tensed.

This tension is so pronounced in today's global exchanges that one wonders whether globalisation has any attribute of globalisation at all. Or is it all about eliminating borders? In the event of globalisation eliminating national borders but failing to eliminate national egos, which manifest in ugly ways in the attitude of the 
citizens, the relationship or interaction between people of diverse cultural background is likely to be characterised by tension. Where we trace the genesis of this tension to the strict and polarised Aristotelian ontology, which draws a line between substance and accident and elevates substance above accident (Aristotle 1926: Book A, 2, 6, 8); Asouzu's Ibuanyidanda construct through the problem of ihe-mkpuchi-anya (phenomenon of concealment) aptly identifies and demonstrates the existence of this tension which promotes various forms of unintended ethnocentric commitments in the global matrix - and also offers a medium through which this tension can be confronted.

\section{CONFRONTING THE TENSION BETWEEN THE "SELF" AND THE "OTHER"}

The thesis of globalisation is opposed to the imposition of the views of a determined individual or people on the rest of humankind. In other words, it is chiefly focused on bringing individuals, peoples and cultures together in such a way as to unify their values, giving everyone equal treatment and recognition in the globalised matrix. But all this can be faulted for ignoring the conditions for proper set-up of globalisation, if the literal meaning of the term itself is anything to go by. Thus, Ibuanyidanda emerges as the nemesis of globalisation as generally conceived in the above. What is meant here is that, as a theory with inclination towards intercultural philosophy (Solomon 2013: 167-168), Ibuanyidanda which harps on the inter-dependence, inter-connectedness and mutual complementarity that necessarily (ought to/must) exist between individuals, peoples and cultures of the world, exposes the challenge of the "self and the other". This challenge naturally emerges when globalisation is conceived and practised merely as a homogenising order that neutralises boundaries and expands views without specifying and insisting that this has to be a mutual exercise in which the ambivalent tension-laden character of our existential conditions are set aside.

Ihe mkpuchi anya, which is an inconspicuous accessory condition, conceals from us this ambivalent tension-laden character of our existential conditions that almost always compels us to elevate the "self" over and above the "other" - unbeknownst to us. Thus, even in our most sincere attempts to reach out to the other, we often end up not exchanging but imposing the "self" on the "other" as the practice of globalisation in our world today portends. We provide little room for the other to thrive whilst actively working to extinguish it and firmly enthrone the self. Our knowledge and understanding of the other become grounded on our often faulty assumptions; it is on the basis of such faulty assumptions that we make ethical judgments about the other and its ontological determinations. The turbulent issues associated with racial tensions, religious crises, ethnic and political tensions in our world today, are cases in point. 
This work reacts against the practice of globalisation in our world today, which seems to hinge on the Aristotelian conception of being as consisting of substance and accident out of which the former is superior to the latter and can subsist without it. In Ibuanyidanda ontology, however, every reality is important and none is negligible - hence the idea of missing links of reality. What this essay therefore rejects in the Aristotelian ontology is the logical principle of bivalence which states that "every statement is either true or false" (Kachi 1996: 1-4). This is replaced by the principle of trivalence which states that "in addition to being true and false, every statement has an intermediate value". This intermediate value is not the Lukasiewiczian "neither true nor false" epistemic interpretation of the undetermined ${ }^{6}$ but the Chimakonian "both true and false" realist reading, called the complementary value. ${ }^{7}$

In the complementary intermediate value, the dialectical process that is capable of producing a harmonious synthesis is made clear. Here, the thesis (True) and antithesis (False) are sub-contraries rather than contradictories and since two sub-contrary positions could both hold, we say that the intermediate value is not undetermined but complementary (True/False) ${ }^{8}$ In it, the properties of seemingly opposed variables subsist and nothing is regarded as dispensable.

When translated into ontological analysis, we notice that all aspects of being are indispensable - hence the Ibuanyidanda thesis that every reality serves a missing link of reality. This is unlike the Aristotelian strict and polarised individualistic ontology where one aspect is superior to the other and can subsist without it. This entails that one aspect, namely accident, is dispensable. My claim has been that globalisation as an ideology enthrones apparent lop-sidedness in the interactions between different peoples, races, religions and cultures of the world by breaching the gap but failing to normalise the ensuing interpersonal relationships.

However, Ibuanyidanda has not gone without criticisms. The celebrated intercultural philosopher, Heinz Kimmerle, ${ }^{9}$ says that the complementary principle of Ibuanyidanda philosophy which leads to a possibility of overcoming the subjectobject dichotomy, is problematic. For him it is inadequate to raise a thoroughgoing subjectivism or thoroughgoing objectivism to a universal methodological principle.

6 Łukasiewicz, Jan. 1970. On three-valued logic. In L. Borkowski (ed.), Selected works by Jan Łukasiewicz, Amsterdam: North-Holland.

7 Chimakonam, J.O. 2013. Principles of indigenous Igbo-African logic: Toward Africa's development and restoration of African identity. Paper presented at the 19th Annual Conference of International Society for African Philosophy and Studies [ISAPS], 50 Years of OAU/AU: Revisiting the Questions of African Unity, Identity and Development. Department of Philosophy, Nnamdi Azikiwe University, Awka, Anambra State. 27-29 May 2013.

8 Chimakonam, J.O. 2012. Building African logic as an algorithm for Africa's development. Paper presented at The University of Georgia, USA, African Studies Institute Conference, 8-10 November.

9 Heinz Kimmerle in Asouzu, 2007b: 13-16. This is an outline of Kimmerle's criticism of Asouzu's thought. 
Asouzu is aware of this problem but does not look at it as a problem. As a matter of fact, it is the dichotomy itself that is the problem. ${ }^{10}$ His idea is that it is the division, polarisation or dichotomisation of interests that has created much of the problems troubling human existence in the world. Such problems as racism, ethnicism, religious fundamentalism and tribalism (manifesting in the form of constant tussle we witness between the "self" and the "other") have brought about irreconcilable problems in the world. Thus, eliminating this dichotomy through a new ontology that portrays the shared values of humankind, the interconnectedness and the mutual inter-dependence becomes for Asouzu a noble philosophical project.

Also, in this same light, Gottlob Frege's admonition "always to separate sharply the psychological from the logical, the subjective from the objective" (Frege 1960: xxii) can be used against the thesis of Ibuanyidanda ontology. For Frege, it is vital that these two are separated and remain separated in all discourses. This is because they have different and opposed structures which portray differences in meaning. Meaning, for Frege, is important - that is why every meaningful statement contains a thought which is its sense (1956: 289-311). To merge or treat the objective as if it could co-exist with the subjective in a common framework, is for Frege to commit an error that will infringe on the meaningfulness of a statement. Ibuanyidanda ontology therefore, in combining the objective and the subjective, would become an episteme full of contradictions.

Asouzu would rather respond that the elements in Ibuanyidanda ontology are not disposed to contradictories, but to harmonisable sub-contraries. There is mutual need of one another by every entity. Reality proves this. Nothing can thrive on its own alone. Everything needs another and in the final analysis, it comes to light that nothing is essentially useless or worthless. This idea of opposition is implicit in Aristotelian ontology where accident is regarded as dispensable. In Ibuanyidanda ontology, everything has its place in the world - bound together by mutual dependence and need. Hence, Frege and others in thinking from the perspective of logical bivalence may not see the sense in complementarity but thinking rather from the perspective of the logical principle of trivalence, it makes a whole lot of sense why Ibuanyidanda is a better interpretation of being than the Aristotelian ontology.

Further still, Chimakonam (2011: 46-48) accuses Ibuanyidanda ontology of over-indulgence and blind generalisation. For Chimakonam, Ibuanyidanda was adapted from the observation of the life-world of danda - a species of ants that live and work together instead of on individual basis. Having observed the amount of success the ants record following this pattern of behaviour, Asouzu went ahead to recommend it for humans and generalise it as a rule of ontology. According to

10 See Asouzu 2011: 16-17. This is a point Asouzu has maintained consistently in his propagation of Ibuanyidanda complementary ontology as a better alternative to Aristotle's static discriminative ontology of essence. 
Chimakonam (2011: 46-48), this is hasty because, humans are not danda; humans are dynamic beings with rationality, intelligence and propensity to individual choice.

In his 2013 book Some basic philosophical problems, Asouzu responds to this criticism. Mesembe Edet also responds to this in a later work (Edet and Chimakonam 2014: 113-14). At its descriptive hypothetical injunction level, Ibu anyi danda falls into this problem of assuming that what works for danda could work for humans (Asouzu 2013: 24-29). But the goal of Ibuanyidanda is more sublime; it aims at transforming that hypothetical injunction ibu anyi danda into a categorical imperative Ibuanyidanda where it ceases to be a descriptive statement of some ant behaviour and becomes a universal maxim applicable to all humans. The way to achieving this includes noetic propaedeutic, which implies the training of the mind; recourse to the transcendent categories of consciousness which enables humans to recognise their mutual inter-dependence and the full personal autonomy through ima onwe onye which enables humans to attain the understanding that whatever touches one, touches the rest. At this level, the descriptive rule of danda "the nearer the better the safer" gives way for a categorical imperative founded on the mutual knowledge, mutual understanding and consciences of humans.

Again, Chimakonam observes that Asouzu's transcendent categories of unity adopted from the Igbo thought, and which includes akara obi/akara mmuo, are not complete. He observes that Asouzu omitted one important category which is akara onwe and akara udi, and that translates to identity and difference (Chimakonam 2011: 46-49). For Chimakonam, therefore, Asouzu's claim that his philosophy has a base in the thoughts of the anonymous Igbo thinkers, runs into problem. This is because these anonymous Igbo thinkers did not totally reject the dichotomy in reality as the category of identity and difference has shown, which is aptly captured in the Igbo proverb "ihe niile gasia, ka osi so onye anaghi aga" meaning, "when everything else has been set aside, the individual will cannot be set aside". Asouzu's response was to explain that his theory was not wholly traditional. He had engaged in a critical individual exercise to create Ibuanyidanda as fresh episteme rather than a complete adaptation of the traditional Igbo thought. In this way it can be argued that not everything in the thoughts of anonymous Igbo thinkers was relevant to the construction of the Ibuanyidanda system.

Chimakonam also criticises Ibuanyidanda as a perfectionist theory ${ }^{11}$ where the dialectical interplay is expected to yield a harmonious complementary synthesis. He also accuses Asouzu of playing with what eventually might be a monstrous onevalued logical system, since the rejection of ontological dichotomy translates to the rejection of contradiction (Asouzu 2004: 280, 319-27). Asouzu responds that the logic of his work is dynamic and recognises the intermediate value. It is a logic of conjunctive reasoning rather than that of disjunctive reasoning as found in Aristotle

11 Chimakonam 2011: 46-49. By perfectionist theory is meant any theory that tends to say that the world would be a perfect place if human beings were to do all it states at all time. 
(Asouzu 2013: 93). Asouzu's point is that although his logic is conjunctive, it is so on account of the intermediate value of say a three or many-valued system and never a one-valued system. Edet also dismisses the perfectionist accusation on the ground that Ibuanyidanda already acknowledges the limitation of being (Edet and Chimakonam 2014: 86). We therefore see that Ibuanyidanda is not without its critics; like any other viable theory and like viable theories it is able to respond to reactions against it.

\section{CONCLUSION}

I have in this work investigated the basis of all forms of tensions that occur and manifest between the "self" and the "other" in our world today under the nose of globalisation and located it in the strict and polarised Aristotelian ontology made manifest by the inherent problem of ihe mkpuchi anya. To counter that, we employed Asouzu's Ibuanyidanda philosophy as a veritable alternative programme that could neutralise the tension and engender a balanced global relationship among diverse cultures and individuals.

It is difficult if not expressly impossible for entities to exist without tension if they were not in this sort of relationship of mutual dependence and interconnection. This implies that globalisation without equity and recognition of otherness is nothing but an imposition of the values of one on the rest of humankind. Nothing is by its nature meant to stand alone ( $k a$ so mu di). The ultimate structure of being is that of interconnectedness and inter-relatedness. This relationship is dialectical and it is through the dialectical process that being evolves from one stage to another. It is possible that when applied as a process of mutual exchanges between globalising cultures, globalisation will stand to offer more in terms of world peace, unity, crosscultural and intercultural understandings.

The knowledge of the tension which ihe mkpuchi anya causes among humans is essential in restoring order and peace in the world. Disorder is as a result of commitments to divisive orientation where humans project self-interests over and above common interests. If it is the natural order that humans live interdependently, then any anti-Ibuanyidanda act that recognises or promotes the division between the "self" and the "other" can only lead to disorder. Some of such disorderly indoctrinations based on anti-Ibuanyidanda acts include: racism, ethnicism, tribalism and religious bigotry. These problems and other forms of orientation that recognise the line between the "self" and the "other" are central to the disorder in the world today.

In this work, I have established with Asouzu that the ultimate cause lies with such theories and orientations that give in to the lure of opposed demarcation of reality into two camps, which go on to accentuate the emergence of ihe mkpuchi anya. In metaphysics we find this in Aristotle's ontology where he analyses being 
as containing two aspects namely: substance and accident. Whereas substance is the ultimate, representing the very substratum of being even in the absence of accident, accident is but a mere manifestation on the senses which is dispensable in the analysis of the basic structure of being. This is the very beginning of the divisive orientation of the "self" and the "other" which we project in this work as lending credence to the structure of globalisation in our world today. Asouzu therefore describes Aristotle's ontology as the philosophy of essence which is divisive, polarising and dichotomising (Asouzu in Chimakonam 2015: 42-45).

To remedy the situation and promote a global exchange that does not uphold the "self" and vitiate the "other" in any form it is practised, Asouzu offers a veritable conception of being, based on the ontology of Ibuanyidanda which is uniting and harmonising.

When we recognise that Aristotle's divisive metaphysics accounts for much of the disorder in the world - whether in terms racial problems, religious fundamentalism, political grand-standings, wars, conflicts, pogroms and mayhems, social injustices, different forms of discriminations and subjugations arising from ethnicism, tribalism, nepotism, feminism and favouritism - then we shall be open to an alternative episteme. Asouzu's theory of Ibuanyidanda ontology in unveiling the challenge posed by ihe mkpuchi anya (phenomenon of concealment), creditably fills that gap by delicately wiping the line between the "self" and the "other" in infusing the idea of missing links and complementarity into our understanding, interpretation and practice of globalisation.

\section{REFERENCES}

Agbo, J.N. 2010. Is globalization a process or a product? In The Humanities and Globalisation in the Third Millennium. Edited by A.B.C. Chiegboka, T.C. Utoh-Ezeajugh and G.I. Udechukwu. Nimo: Rex Charles \& Patrick, p. 26-39.

Aristotle. 1926. Metaphysics. Translated into English under the editorship of W.D. Ross. Oxford. Vol. VIII, Second Edition. Oxford: Clarendon Press.

Asouzu, I. 2004. The method and principles of complementary reflection in and beyond African philosophy. Calabar: University of Calabar Press.

Asouzu, I. 2007a. Ikwa Ogwe essential readings in complementary reflection. Calabar: Saesprint Publishers.

Asouzu, I. 2007b. Ibuaru, the heavy burden of philosophy beyond African philosophy. London: Transaction Publishers.

Asouzu, I. 2007c. Ibuanyidanda, new complementary ontology beyond world-Immanentism, ethnocentric reduction and impositions. London: Transaction Publishers.

Asouzu, I. 2011. Ibuanyidanda and the philosophy of essence. Philosophy, the science of missing links of reality. $50^{\text {th }}$ Inaugural Lecture, University of Calabar. Calabar: University of Calabar Press. 
Asouzu, I. 2013. Ibuanyidanda and some basic philosophical problems in Africa today. Zurich: Lit Verlag.

Asouzu, I. 2015. The question of being in African philosophy: A case for Ibuanyidanda ontology". In Atuolu Omalu: Some unanswered questions in contemporary African philosophy. Edited by J.O. Chimakonam. Lanham: University Press of America, p. 35-52.

Ayer, A.J. 1952. Language truth and logic. New York: Dover Publications.

Chimakonam, J.O. 2011. Dissecting the character of Danda the Ant and neutralizing the philosophy of missing links: An Egbe N'ugo Conundrum. Journal of Complementary Reflection: Studies in Asouzu, October, 1(1): 41-51, ISSN 2026-6545.

Chimakonam, J.O. 2012. Building African logic as an algorithm for Africa's development. Paper presented at the University of Georgia, USA, African Studies Institute Conference, Nov. $8-10$.

Chimakonam, J.O. 2013. Principles of indigenous Igbo-African logic: Toward Africa's development and restoration of African identity. Paper presented at the $19^{\text {th }}$ Annual Conference of International Society for African Philosophy and Studies [ISAPS], 50 Years of OAU/AU: Revisiting the questions of African unity, identity and development. Department of Philosophy, Nnamdi Azikiwe University, Awka, Anambra State. 27-29 May.Edet. M. and Chimakonam, J.O. 2014. Ibuanyidanda as "Ezi Okwu" and the resolution of Chimakonam's Egbe N'ugo conundrum: A response to J.O. Chimakonam's dissecting the character of Danda the Ant and neutralizing the philosophy of missing links. In Arguments and clarifications: A philosophical encounter between J.O. Chimakonam and M.I. Edet on the Ibuanyidandaness of complementary ontology, M. Edet and J.O. Chimakonam. Calabar: $3^{\text {rd }}$ Logic Option.

El-Ojeili, C. and Hayden, P. 2006. Critical theories of globalization. New York: Palgrave Macmillan.

Flew, A. 1990. An introduction to Western philosophy. In Knowing Philosophy, J. Omoregbe. Lagos: Joja Publications.

Frege, G. 1956. The thought: A logical inquiry. Mind: A Quarterly Review of Psychology and Philosophy (New series, July) 65(259): 289-311.

Frege, G. 1960. The foundations of arithmetic: A logico-mathematical enquiry into the concept of number (2nd Revised edition). Translated by J.L. Austin. New York: Harper and Bothers.

Kimmerle, H. 2007. Reaction to Innocent Asouzu's approach to African philosophy and the context of other interpretations, 13-23. In Ibuaru, The heavy burden of philosophy beyond African philosophy. I. Asouzu. London: Transaction Publishers.

Kachi, D. 1996. Was Lukasiewicz wrong? Three-valued logic and determinism. Paper presented at Lukasiewicz in Dublin - An International Conference on the Works of Jan Lukasiewicz, 7 July.

Lawson, T. 2004. A conception of ontology. Cambridge papers: Version 2004.

Łukasiewicz, J. 1970. On three-valued logic. In Selected works by Jan Łukasiewicz. Edited by L. Borkowski. Amsterdam: North-Holland, p. 87-88.

Russell, B. 1996. History of Western philosophy. London: Routledge.

Sogolo, G. 1993. Foundations of African philosophy: A definitive analysis of conceptual issues in African thought. Ibadan: Ibadan University Press. 
Solomon, K.C. 2013. The challenge of intercultural philosophy and integrative humanism. Journal of Integrative Humanism 3(1): 163-187.

Wiredu, K. 1980. Philosophy and an African culture. Cambridge and New York: Cambridge University Press. 